\section{Evaluation of help by a potential recipient}

\author{
BENSON ROSEN \\ Graduate School of Business Administration \\ University of North Carolina, Chapel Hill, N.C. 27514
}

In order to test the hypothesis that the decision to accept or reject a prosocial offer is a joint function of (1) value and cost associated with the offer and (2) the recipients degree of dependence, a role-playing abilities test was created. As part of the role-playing task, undergraduate students were asked to consider a prosocial offer, consisting of either high or low value, which imposed minimal or restrictive constraints, under conditions of high or low dependence. As predicted, high value and low cost were significant factors in the decision to accept or reject the prosocial offer. In addition, two unexpected interactions, Value by Dependence and Cost by Dependence, were significant.

At many levels of society, an important but seldom investigated problem is the administration of help. Since dispensing and receiving help is a prominent activity in everyday behavior, the conditions leading to acceptance or refusal and other reactions to help deserve careful investigation.

Prosocial behavior is here defined as an action by a source (the donor) which results in another person's (the recipient) moving to a more favorable reward-cost position than existed prior to the action. The more favorable reward-cost position may be achieved by an increase in the recipient's level of rewards and/or a decrease in his costs; the donor may be a specific other, an informal group, or a formal organization. Note that this definition differs from Sawyer's (1966) conceptualization of altruism, namely: "the value one places on the welfare of another in relation to his own welfare." That is, a prosocial act, as stated here, may or may not be an altruistic one.

Previous research has emphasized the problems of "when" and "why" prosocial or helping behavior occurs. Investigators, employing laboratory and naturalistic experimental designs, have demonstrated relationships between prosocial behavior and: (1) past experience of the benefactor (Berkowitz \& Daniels, 1964 ; Berkowitz \& Connor, 1966; Berkowitz \& Friedman, 1967; Greenglass, 1969); (2) attraction to the recipient (Daniels \& Berkowit2, 1963; Rosen \& Bielefeld, 1967; Feldman, 1968); (3) locus of dependence (Schopler \& Matthews, 1965; Horowitz, 1970); and (4) observation of a model engaging in a prosocial act (Bryan \& Test, 1967; Hornstein, Fisch, \& Holmes, 1968; Wagner \& Wheeler, 1969).

Little research, on the other hand, has been concerned with the recipient of assistance. Of those studies focusing on the recipient, all have examined his reactions after receiving a favor or help. Gouldner (1960) postulated a norm of reciprocity as the motivational force underlying the behavior of recipients. Reciprocity implies the internalization of norms that oblige a recipient to repay his benefactor and varies according to the needs and motives of both parties engaged in prosocial interaction.

The need state of an original recipient mediating his willingness to reciprocate has been demonstrated in three studies (Pruitt, 1968; Frisch \& Greenberg, 1968; Leventhal, Weiss, \& Long, 1969). Consistently, greater reciprocity was found for Ss receiving large rather than small amounts of help. In addition, when a donor acted on his own free will rather than accidentally or because of role pressures, recipients were more willing to reciprocate (Goranson \& Berkowitz, 1966; Frisch \& Greenberg, 1968; Leventhal, Weiss, \& Long, 1969).

Motives attributed to the original donor alter the recipients adherence to norms of reciprocity. Brehm \& Cole (1966) have shown that a favor which is perceived as constraining a recipient's freedom is not reciprocated, and Schopler \& Thompson (1968) have demonstrated that attribution of motives to a donor mediates the degree of reciprocation.

From the research cited, it should be obvious that examination of the determinants of a prosocial act has been limited to factors which induce a potential benefactor to give help and factors that influence a recipient's decision to reciprocate. The present research focuses on another aspect of prosocial behavior, the factors that affect a potential recipient's decision to accept help. Specifically, the study is an attempt to provide information concerning the effects of value, cost, and dependency on a potential recipient's reactions to an offer of help. The probability that help will be accepted is hypothesized to increase as the value of the offer increases and decrease as the costs imposed on the potential recipient increase, Costs of receiving help are broadly defined to include the physical and psychological sacrifices to-and behavioral constraints imposed on-the potential recipient. In addition, an interaction is predicted between the recipient's level of dependence (where dependence represents a lack of resources for reaching a specific goal) and the value and cost variables. It is suggested that offers of low value and/or high cost will be more readily accepted by highly dependent recipients than would similar offers to less dependent recipients.

\section{SUBJECTS}

The Ss were 160 undergraduate males and females enrolled in the introductory psychology courses at Wayne State University. Participation in the experiment fulfilled part of the course requirements.

\section{PROCEDURE}

In order to study the relationship between the variables under consideration, the guise of a role-playing abilities test was used. ${ }^{1}$ Ss received booklets containing biographical information about a handicapped student, named Donald Hollander, who was about to be interviewed for a college scholarship. Ss were told that their ability to role play would be determined by the similarity of their responses and impressions to the actual responses and impression of the person whose role they were playing.

As a test of their role-playing ability, Ss were instructed to play the role of the handicapped student at a scholarship interview. They completed what appeared to be a transcript of the scholarship interview by supplying the dialogue for the handicapped student. Ss were then presented with a detailed description of a college scholarship and instructed to state their decision to accept or reject the scholarship offer.

\section{Independent Variables}

The three independent variables were: (1) the value of the help offered; (2) the behavioral constraints imposed on the recipient; and (3) the recipient's level of dependence. Each variable was manipulated at two levels, resulting in a 2 by 2 by 2 factorial design. Accordingly, eight variations of the role-playing test booklet were written.

The biographical information describing the handicapped student contained the manipulation of the dependence. In the high-dependence condition, the biography stated: "Unfortunately, his parents are not able to finance his college education. Since Donald would have to live on campus, the cost of room and board in addition to the expenses for books and tuition would pose a serious problem." 
Table 1

Number of Ss Accepting the Prosocial Offer*

\begin{tabular}{lcccccc}
\hline & \multicolumn{2}{c}{ High Dependence } & & \multicolumn{2}{c}{ Low Dependence } \\
\cline { 2 - 6 } & High Value & Low Value & High Value & Low Value & Mean \\
\hline High Cost & 16 & 5 & 13 & 10 & 11 \\
Low Cost & 18 & 5 & 19 & 17 & 14.75 \\
Mean & 17 & 5 & 16 & 13.50 & 12.88 \\
\hline
\end{tabular}

$* N=20$ per condition

Biographical information in the low-dependence condition stated: "Fortunately, his parents are able to finance his college education. His parents believe that they could afford the expenses of room and board as well as books and tuition, if necessary."

Four combinations of the scholarship offer provided the manipulation of the value and cost variables. Value of the assistance consisted of two levels: yearly scholarships of $\$ 300$ or $\$ 2,000$. Similarly, cost to the recipient was varied by increasing the nature and number of behavioral constraints imposed on the scholarship recipient. In the low-cost condition, the scholarship recipient was merely requested to report his grades each semester, while in the high-cost condition, the recipient had to agree to participate in an elaborate publicity campaign and promotion of the scholarship fund.

Dependent Variable

The dependent variable was assessed within the context of the "role-playing test." Data analysis for the dependent variable took the form of a 2 by 2 by 2 factorial design, with 20 Ss assigned randomly to each of the eight conditions. The dichotomous dependent variable, acceptance or rejection of the prosocial offer, was analyzed according to Goodman's procedure (1964) for testing interactions in contingency tables.

$$
\text { RESULTS }
$$

Tests of the Effectiveness of

the Experimental Manipulations

Since the manipulation of three independent variables - value, cost, and dependence-were included in the paper-and-pencil test of role-playing ability, it was essential to check on the effectiveness of the experimental manipulations.

Value manipulation. The check on the value manipulation was determined by Ss' responses to Question A in the test booklet, "How valuable do you think the scholarship offer is perceived to be by Donald Hollander?" Ss indicated their perceived value by marking a 7 -point scale ranging from "extremely valuable" to "extremely valueless." The mean for $S s$ in the high-value condition was 6.4 compared to a mean of 4.7 in the low-value condition $(t=4.9$, df $=1,58, p<.001)$.

Cost manipulation. Question B of the role-playing abilities test asked, "How humiliating or restricting were the scholarship regulations for Donald Hollander?" Ss indicated their perceptions of the scholarship's restrictiveness on a 4-point scale, ranging from "not at all restrictive" to "extremely restrictive." Mean rating of restrictiveness in the high-cost condition was 2.16 compared to a mean rating in the low-cost condition of $1.38(t=3.9$, df $=1,58, p<.001)$.

Manipulation of dependence. A check on the manipulation of dependence was determined by asking Ss to recall biographical information related to Hollander's financial position. Financial assistance from parents to supplement the scholarship offer was mentioned by $56 \%$ of the Ss in the low-dependence condition, while none of the $S$ s in the high-sependence condition indicated other sources of financial assistance. On the basis of these results, it appears that the three variables, value, cost, and dependence, were successfully manipulated by the role-playing task. Acceptance of the Prosocial Offer

It was hypothesized that a person's willingness to accept or reject an offer of assistance was determined by the value of the offer, the cost imposed on the recipient, and the recipient's level of dependence. Table 1 shows the number of $\mathrm{Ss}$ accepting the prosocial of fer in each of the eight conditions. A chi-square analysis for acceptance or rejection of the prosocial offer yielded significant main effects for value $(\mathrm{p}<.01), \quad$ cost $(\mathrm{p}<.05)$, and dependence $(p<.05)$. High value, low cost, and low dependence significantly increased the probability that the prosocial offer would be accepted and, therefore, strongly support the hypothesis.

Goodman's (1964) technique for testing the interactions in contingency tables indicated that two first-order interactions were significant. ${ }^{2}$ It is obvious from Table 1 that the significant Value by Dependence interaction $(p<.01)$ was due to the large difference between high and low dependence for the low-value prosocial offer. Contrary to the hypothesis, Ss were more willing to accept a low-value offer in the low-dependence condition.

The nature of the significant Cost by Dependence interaction $(p<.05)$ is also shown in Table 1 . When cost of accepting was high, no difference was found between the high- and low-dependence conditions. For low-cost offers, however, dependence was important in the decision to accept or reject the offer. Unexpectedly, Ss in the low-dependence condition were more willing to accept the low-cost offer than $S$ s who lacked additional resources (high dependence).

It appears that for highly dependent recipients, the decision to accept help is determined by the value of the offer. On the other hand, costs associated with the offer appear to mediate the decision to accept or reject help for Ss in the low-dependence conditions, and, as the recipient is forced to incur greater costs, the probability of rejection increases.

\section{DISCUSSION}

An attempt was made to describe the processes underlying a prosocial interaction. Because of the role-playing methodology, findings are based on 'Ss' conceptions of how people would respond rather than on actual behavior, and there may be some differences between the two cases. Generality of results must bo qualified accordingly.

The significant main effects with regard to value and cost are consistent with intuition, as well as some empirical research. Results indicated that Ss were more willing to accept high-value than low-value offers of help. This finding is consistent with research examining reciprocity of highand low-value help (Pruitt, 1968; Frisch \& Greenberg, 1968; Leventhal, Weiss, \& Long, 1969). Regardless of dependence level, most Ss were willing to incur high costs for highly valued help.

A number of researchers (Brehm \& Cole, 1966; Wagner \& Wheeler, 1969; Jones, 1970), interested in the determinants of prosocial behavior, have acknowledged the importance of costs incurred by the benefactor. In the Jones study, for example, Ss in the high-choice condition were less willing to assist a person in great need of help compared to a "slightly" needy person, particularly when it appeared that the needy person would ask for additional assistance in the future. In order for many prosocial acts to occur, the recipient, as well as the benefactor, must give his consent. Previous research, by examining only the benefactor's costs and ignoring the recipient's costs, have presented a 
distorted picture of the prosocial interaction. The cost concept is equally applicable to the recipient of a prosocial act. Cost to the recipient was found to be an important factor in determining his decision to accept or reject a prosocial offer, particularly when the prosocial offer was of low value and the recipient had additional resources.

The more interesting and nonobvious findings of this study derive from the main effect for the dependence variable and the significant first-order interactions. While previous studies considered the relationship between a recipient's dependence and the generosity of his benefactor, the present research emphasizes the importance of a recipient's dependence in determining his decision to accept or reject help. This distinction proved important, as evidenced by the significant Value by Dependence interaction. It was expected that a low-value offer in the face of poor alternatives would be readily accepted. Contrary results were obtained, however, indicating that some "disutility" may be associated with a low-value offer under high dependence.

Prior to reaching a decision to accept or reject assistance, $S$ undoubtedly consider the adequacy of a prosocial offer for reaching a desired goal. It is assumed, in the present discussion, that the goal does not change because of adaptation effects or as a result of changes in aspiration level. A high-value offer represents a sufficient condition for reaching a desired goal and, therefore, should be willingly accepted. Moreover, at a particular aspiration level, low-value offers in the low-dependency condition might be combined with other resources and also represent sufficient reason for accepting the offer. One explanation for the Value by Dependence interaction is that low-value offers appear helpful to potential recipients only when combined with additional resources. REFERENCĒS

BERKOWITZ, L., \& CONNOR, W. H. Success, failure, and social responsibility Journal of Abnormal \& Social Psychology, 1966, 4, 664-669.

BERKOWITZ, L., \& DANIELS, L. R. Affecting the salience of the social responsibility norm: Effects of past help on thy response to dependency relationships. Joumal of Abnormal \& Social Psychology, 1964, 68, 275-281.

BERKOWITZ, L., \& FRIEDMAN, P. Some social class differences in helping behavior. Journal of Personality \& Social Psychology, 1967, 5, 217-225.

BREHM, J. W., \& COLE, A. H. Effects of a favor which reduces freedom. Journal of Personality \& Social Psychology, 1966, 3, 420-426.

BRYAN, J. H., \& DAVENPORT, M. Donations to the needy: Correlates of financial contributions to the destitute. Unpublished manuscript, Educational Testing Service, Princeton, N.J., 1968.
BRY AN, J. H., \& TEST, M. A. Models and help: Naturalistic studies in aiding behavior. Journal of Personality \& Social Psychology, 1967, 6, 400-407.

DANIELS, L. R., \& BERKOWITZ、 $L$. Liking and responses to dependency relationships. Human Relations, 1963. 16. 141-148.

FELDMAN, R. E. Response to compatriot and foreigner who seek assistance Journal of Personality \& Social Psycho$\operatorname{logy}, 1968,10,202-214$

FREEDMAN, J. L. Role playing: Psychology by consensus. Journal of Personality \& Social Psychology, 1969, 13, 107-114.

FRISCH, D. M., \& GREENBERG, M. S. Reciprocity and intentionality in the giving of help. Proceedings of the $76 \mathrm{th}$ Annual Convention of the American Psychological Association, 1968, 3, 383-384.

GOODMAN, L. Interaction in contingency tables. American Statistical Association Journal, 1964, 319-352.

GORANSON, R., \& BERKOWITZ, L. Reciprocity and responsibility reactions to prior help. Journal of Personality \& Social Psychology, 1966, 3, 227-232.

GOULDNER, A. W. The norm of reciprocity: A preliminary statement. American Sociological Review, 1960, 25 . 161-178.

GREENBERG, M. S. Role playing: An alternative to deception. Journal of Personality \& Social Psychology, 1967. 7, $152-157$.

GREENGLASS, E. R. Effects of prior help and hindrance on willingness to help another: Reciprocity or social responsibility. Journal of Personality \& Social Psychology, 1969, 11, 224-231.

HORNSTEIN, H. A., FISCH, E., \& HOLMES, $M$. Influence of a model's feelings about his behavior and his relevance as a comparison other on observers' helping behavior. Journal of Personality \& Social Psychology, 1968, 10, 222-227.

HOROWITZ, I. A. Effects of choice and locus of dependency of helping behavior. Journal of Personality \& Social Psychology, 1970, 14, 224-226.

HOROWITZ, I., \& ROTHSCHILD, Conformity as a function of deception and role playing. Joumal of Personality \& Social Psychology, 1970, 14, 224-226.
JONES, R. A. Volunteering to nelp: The effects of choice, dependence and anticipated dependence. Joumal of Personality \& Social Psychology, 1970, 14, 121-129.

LEVENTHAL, G. S., WEISS, T., \& LONG, G. Equity, reciprocity and re-allocation of rewards in the dyad. Journal of Personality \& Social Psychology, 1969. 13, 300-306.

PRUITT, D. G. Reciprocity and credit building in a laboratory dyad. Journal of Personality \& Social Psychology, 1968, 5. 143-147.

ROSEN, S., \& BIELEFIELD, R. J. Help received by a needy competitor as contingent upon the deference he shows. Paper presented at the American Psychological Association, Washington, D.C., 1967 .

SAWYER, J. The altruism scale: A measure of co-operative, individualistic, and competitive interpersonal orientation. The American Joumal of Sociology, $1966,71,407-416$.

SCHOPLER, J., \& MATTHEWS, M. W. The influence of perceived causal locus of a partner's dependence on the use of interpersonal power. Joumal of Personality \& Social Psychology, 1965, 2 , 609-612.

SCHOPLER, J., THOMPSON, V. D. Role of attribution processes in mediating amount of reciprocity for a favor. Journal of Personality \& Social Psychology, 1968, $10,243-251$

TESSER, A, GATEWOOD, $R$, DRIVER, $M$. Some determinants of gratitude. Journal of Personality \& Social Psychology, 1968, 9, 233-236.

WAGNER, C., \& WHEELER, L. Model, need, and cost effects on helping behavior. Journal of Personality \& Social Psychology, 1969, 12, 111-117.

1. Although Freedman (1969) has criticized the use of role playing experimental techniques, recent methodological studies (Greenberg, 1967; Horowitz \& Rothschild, 1970) have demonstrated that role playing can be an effective substitute for deception. Moreover, Tesser et al's (1968) research is certainly based on this tradition, i.e., it relied on vicarious or "as if" experience.

2. The author wishes to acknowledge the advice of $J$. E. Keith Smith in the analysis of portions of the data.

\title{
Formation, maintenance, generalization, and retention of response hierarchies: Persistence of differences due to meaningfulness of response members*
}

\author{
ALBERT E. GOSS \\ Rutgers - The State University, Douglass College, New Brunswick, N.J. 08903
}

Anticipation and recall of alternative response members of high or low meaningfulness (M) is assessed through four daily cycles of 120 trials under 50-50 percentages of occurrence and of additional trials with response members omitted both in acquisition and in simulated word-association situations. For whole lists across Ss and for units within lists for individual Ss, response members of high $\mathrm{M}$ are anticipated and recalled more frequently than those of low M. These differences occur in the first cycle; they increase and hold through the last three cycles.

Formation of response hierarchies by means of divergent paired-associates (PA) units is influenced by meaningfulness $(M)$ of 